\title{
Loupe with magnifying lens as an aid to difficult intubation
}

\author{
Suresh K Singhal ${ }^{1}$, Kiranpreet Kaur ${ }^{2}$, Anil K Thakur ${ }^{3}$ Jagdish Chander Dureja ${ }^{4}$, \\ Senior Professor ${ }^{1}$, Assistant Professor ${ }^{2}$, Associate Professor ${ }^{3}$, Professor $^{4}$, PGIMS, Rohtak, India.
}

*Corresponding author : kiranpreet72@ rediffmail.com

\begin{abstract}
Unpredicted non visualisation of larynx after induction is a big problem for every anaesthetist. It is not always possible to predict whether tracheal intubation will be difficult or even impossible. Various maneuvers and gadgets have been used from time to time to visualize the larynx. A four months old infant with diagnosis of Tetralogy of Fallot's was posted for total correction. We encountered a difficult airway situation and we used the surgeon's Loupe with magnifying lens of power $3.5 \mathrm{X}$, which to our surprise made visualization of the airway appreciable and we succeeded in intubating the patient without any further attempts.
\end{abstract}

Keywords : difficult airway, difficult airway gadgets

\section{Introduction:}

Unpredicted non visualisation of larynx after induction is a nightmare for every anaesthetist. It is not always possible to predict whether tracheal intubation will be difficult or even impossible. Various maneuvers and gadgets have been used from time to time to visualize the larynx. In infants, vocal cord access may be slightly more problematic because of certain anatomical variations: the tongue is large relative to the mandible and the larynx is more cephalad than in the older child, the epiglottis in infants is hard and is folded into an inverted $U$ shape. In infants below the age of four months the epiglottis is at the level of the first cervical vertebra; at six months it has moved down to the level of the third cervical vertebra. ${ }^{1}$

\section{Case report:}

A four month old infant with diagnosis of Tetralogy of Fallot was posted for total correction. After obtaining the informed written consent from the parents, the child was shifted to the operation theatre. On arrival monitoring devices were placed and general anaesthesia was administered. Induction of anaesthesia was as a routine cardiac induction. On laryngoscopy, vocal cords could not be visualised as the epiglottis was quite large with a markedly anterior larynx. Even after lifting the epiglottis the glottis opening was not clearly seen and the endotracheal tube was slipping into the oesophagus. Second attempt with endotracheal tube with stylet in situ was done but was unsuccessful. The problem in intubating the child was also augmented because of the poor light of the laryngoscope and poor appreciation of glottic and esophageal opening. Thus we used surgeon's Loupe with magnifying lens of power 3.5 $\mathrm{X}$, which to our surprise made things so visible that we succeeded in intubating the patient. After that we are using this magnifying loupe for intubating neonates and infants and it makes the task easy.

\section{Discussion:}

Various methods to handle difficult airway situations in chidren have been recommended in literature like the use of Laryngeal mask airway (LMA), intubating LMA, fibreoptic intubation etc. ${ }^{1}$ But we used loupe with lens in an emergency situation to handle a difficult airway. Surgeons in many specialties like cardiac, vascular, plastic, opthalmic, dental surgery etc commonly use these magnifying loupes when doing surgery on delicate structures particuarly vascular anastomosis. The Loupes used by surgeons are mounted on the lenses of glasses and can be custom made for individual surgeon, taking into account their corrected vision, interpupillary distance and desired focal distance. (Fig-1). 
Figure- 1: Loupe with lens

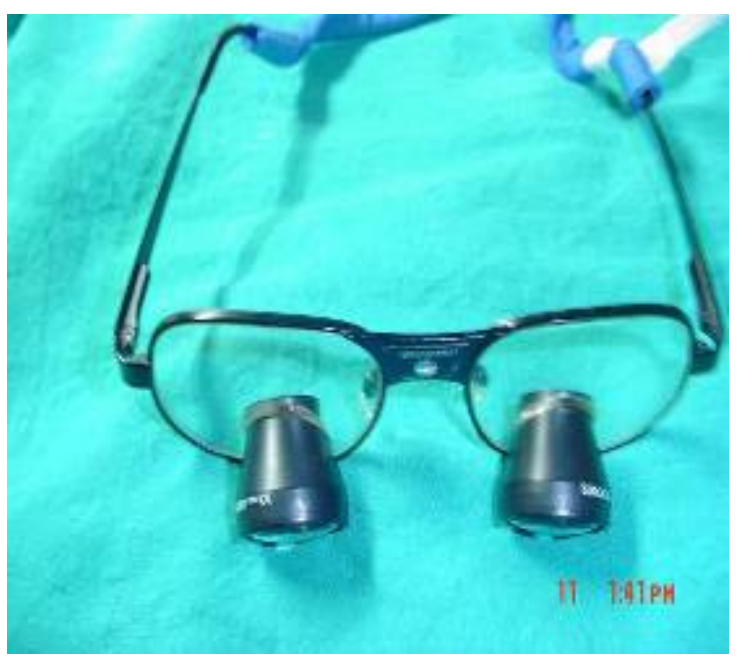

Multiple magnification powers of the loupes are available. ${ }^{2}$ In anaesthesia there is aways a scope for innovations. Previously also many equipments meant primarily for different use have came to the rescue of the anaesthesiologist in difficult scenarios like the indirect laryngoscopy mirror and dental mirror for intubation. ${ }^{3,4}$ These equipments are simple to use, inexpensive and maintenance free. Indirect laryngoscopy mirror is freqently used by otolaryngologist and dental mirror by dentist. Application of these gadgets is not common in anaesthesia practice, but can be used in cases of difficult intubation. Conventional indirect laryngoscopy is, however, difficult for anesthesiologists because they are unaccustomed to using the head and the laryngeal mirrors. Visualization of the larynx by indirect laryngoscopy requires that anesthesiologists not familiar with the technique acquire some experience to become proficient. ${ }^{3}$ Thus we feel that this loupe with magnifying lens can be a rescue tool during laryngoscopy and intubation in neonates and infants.

\section{References:}

1.Walker RWM. Management of the difficult airway in children. J R Soc Med. 2001; 94(7): 341-44.

\section{PMid:11418704 PMCid:1281598}

2. 'Loupe' From Wikipedia, the free encyclopedia. http://en.wikipedia.org/wiki/Loupe

3. Ken Y, TsunehisaT; Keizo S; Shigeo O; Shunichi $\mathrm{N}$; Tsutomu K. Predicting Difficult Intubation with Indirect Laryngoscopy. Anesthesiology 1997; 86 (2): 316-21. http://dx.doi.org/10.1097/00000542-19970200000007 PMid:9054250

4. Yokoyama T, Yamashita K, and Manabe M. Dental Mirror is a Relief for Difficult Endotracheal Intubation. Anesth Analg 2006; 103:1059-1059-a.

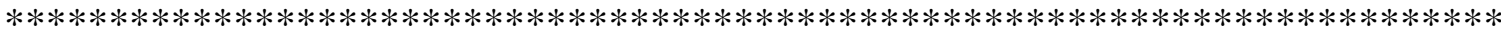

\section{THE COLLEGE OF ANAESTHESIOLOGISTS OF SRI LANKA}

\section{M VATTYGALLE PRIZE COMPETITION:}

The rules of the competition are:

1. Open to all medical practitioners holding a non-consultant appointment in Anaesthesia.

2. Duration of the presentation must be no longer than 15 minutes.

3. The work in whole or in part should not have been presented or published elsewhere.

4. An abstract of not more than 200 words should be submitted before the closing date and the entire paper one month before the sessions.

5. The panel of judges may make a preliminary selection of the papers to be presented at the sessions.

6. The first right of publication of the entries submitted lies with the Editor of the College of Anaesthesiologists of Sri Lanka.

7. The decision of the panel of judges in all matters relating to the competition including questions relating to eligibility shall be final.

8. The prize will not be awarded if the Judges decide the presentation is not up to standard.

The closing date for the 2013 competition is $\mathbf{3 1}$ st October 2012. The abstract should reach the Secretary of the College of Anaesthesiologists of Sri Lanka before the closing date. 3 copies of the full text should be submitted on or before $21^{\text {st }}$ December 2012 to the Secretary of the College. 